\title{
KINETIC STUDY UNDER NON-ISOTHERMAL CONDITION FOR SILICON PURIFICATION
}

\author{
Rodrigo Ramos Silva' \\ Willian Boneli De Almeida' \\ Rozineide Aparecida Antunes Boca Santa' \\ Elídio Angioletto' \\ Humberto Gracher Riella
}

\begin{abstract}
This study aims to evaluate the process of acid leaching, in $\mathrm{HCl}$, for purification of silicon metal, obtained by magnesiothermic reduction of silica and promote greater removal of impurities. The reaction product formed is a powder which is physically and/or chemically bound, with approximately $75 \%$ of $\mathrm{MgO}$ and approximately $25 \%$ of silicon metal, among other elements. Acid leaching is an technique used in the solubilization of oxides by an acid solvent. The silicon metal with purities up to $94 \%$ can be obtained in one step. Thus, it has been tested the effect of the following concentration of hydrochloric acid $\mathrm{HCl}(\mathrm{I}, 2$, and $3 \mathrm{M})$, temperature $\left(50,65\right.$, and $\left.80^{\circ} \mathrm{C}\right)$ and time $(60,90$ and $\mathrm{I} 20 \mathrm{~min})$. The leaching kinetics was studied under non-isothermal condition. After the treatments, it was shown that concentration is the main effect of leaching. In some analyses, it was possible to convert up to $76 \%$, i.e., $99.66 \%$ of $\mathrm{MgO}$ has been extracted.
\end{abstract}

Keywords: Kinetics; Non-isothermal condition; Magnesiothermic; Silicon.

\section{ESTUDO CINÉTICO EM CONDIÇÕES NÃO ISOTÉRMICAS PARA PURIFICAÇÃ̃o DE SILÍCIO}

\section{Resumo}

Este trabalho teve como objetivo avaliar o processo de lixiviação ácida em $\mathrm{HCl}$ para remoção de impurezas e purificação de silício metálico obtido por redução magnesiotérmica de sílica. O produto de reacção formado é um pó que está fisicamente e/ou quimicamente ligado, com cerca de $75 \%$ de $\mathrm{MgO}$ e aproximadamente $25 \%$ de silício metálico, entre outros elementos. A lixiviação ácida é uma técnica utilizada na solubilização de óxidos por um solvente ácido. O silício metálico com purezas até $94 \%$ pode ser obtido em uma etapa. Assim, foi testado o efeito da seguinte concentração de ácido clorídrico $\mathrm{HCl}(\mathrm{I}, 2$ e $3 \mathrm{M})$, temperatura $\left(50,65\right.$ e $\left.80^{\circ} \mathrm{C}\right)$ e tempo $(60$, 90 e $120 \mathrm{~min})$. A cinética de lixiviação foi estudada sob condições não-isotérmicas. Após os tratamentos, foi demonstrado que a concentração é o principal efeito da lixiviação. Em algumas análises, foi possível converter até $76 \%$, isto é, $99,66 \%$ de $\mathrm{MgO}$ foram extraídos.

Palavras-Chave: Cinética; Condições não-isotermicas; Silício; Magnesiotérmica.

\section{INTRODUCTION}

Estimated that the consumption of siliconuntil 2019 may reach up to 3.6 million metric tons of raw material [I]. Silicon is used in the form of quartz sand, clay, metal alloys, composites, semiconductors and silicones, among others.

Carbothermal reduction of silica is the main way of obtaining silicon, and it is held in submerged-arc electric furnaces, reaching $99.5 \%$ of purity. However, there are other forms of reduction for obtaining silicon [2], e.g., magnesiothermic reduction, forming silicon and $\mathrm{MgO}$ through reduction of quartz by gaseous magnesium $[3,4]$.

The result of the reaction is a powder that is physically and/or chemically bound, with approximately $75 \%$ of magnesium oxide $(\mathrm{MgO})$, approximately $25 \%$ of silicon

'Departamento de Engenharia Química e Engenharia de Alimentos, Universidade Federal de Santa Catarina - UFSC, Florianópolis, SC, Brasil.

E-mail: roosebs@gmail.com

${ }^{2}$ Departamento de Engenharia Química, Universidade do Extremo Sul Catarinense - UNESC, Criciúma, SC, Brasil. 
metal, among other chemical species formed, according to the conditions of the reduction process $[3,4]$.

The silicon metal purification technique, obtained by magnesiothermic reduction, is well grounded in the literature for the solubilization of oxides via an acid solvent, promoting acid leaching [3,5-8]. Through acid leaching, solubilization can be performed for Si purification.

Understanding the mechanisms of chemical dissolution of oxides in aqueous acidic solutions is crucial for a wide variety of processes, including, for example, geochemical and environmental, hydrometallurgical, corrosive, catalyst processes, as well as drug delivery. The many events involved in the leaching process require an extensive series of multidisciplinary knowledge beyond the scope of this study.

Raschman, Fedoročková $[9,10]$ in their work they performed dissolution of $\mathrm{MgO}$ under isothermal conditions. However, the literature lacks studies, in the non-isothermal system, to purification of reaction products obtained by magnesiothermic reduction of silica.

Thus, this research was conducted with the objective of evaluating the process of acid leaching for purification of silicon metal by the magnesiothermic reduction of silica, in order achieve the greatest recovery (yield) of silicon metal at a given concentration, temperature and time, in a single step. In this way, the experiment used a factorial design with $2^{3}$ factors +3 center points, in order to investigate the possible effects and/or combinations of effects resulting from the variation of concentration, temperature and time. Based on the results of each treatment, a kinetic study was performed on leaching under non-isothermal conditions.

\section{MATERIALS AND METHODS}

The powder, the reaction product of the magnesiothermic reduction of silica, was obtained in batches in a pit furnace with $7.0 \mathrm{~kW}$ of power at the Nuclear and Energy Research Institute of the Federal University of São Paulo (IPEN-USP).

The solid reagents used in the reduction were the following: high purity silica and magnesium flakes, which have received heat treatment $\left(700-830^{\circ} \mathrm{C}\right)$, required to promote the reaction between reagents.

The powder was leached with hydrochloric acid $(\mathrm{HCl})$ (Vetec), with a concentration of $37 \%$, in a $500 \mathrm{~mL}$ jacketed batch reactor. According to the factorial design of the experiment, the effect of variation of the following factors was investigated: concentration (hydrochloric acid - $\mathrm{HCl}$ at concentrations of $\mathrm{I}, 2$ and $3 \mathrm{M}$ ), temperature $\left(50,65\right.$, and $\left.80^{\circ} \mathrm{C}\right)$ and time $(60,90$ and $120 \mathrm{~min})$. In addition to a statistical study, $\mathrm{pH}$ was monitored in real time to evaluate in a complementary fashion the kinetic behavior of leaching under non-isothermal conditions in all runs.

The experiments were carried out in a reactor with useful volume of $500 \mathrm{~mL}$, a mechanical shaker with speed set at 600 RPM (with a PTFE-coated stir bar), thermostatic bath for temperature control and $\mathrm{pH}$ monitoring.
Dilutions were performed acontaining I, 2 and $3 \mathrm{M}$, considering IM of $\mathrm{MgO}$, as well as the other chemical species, to ensure the molar ratio of $1: 1,2: 1$ and $3: 1 \mathrm{HCl}: \mathrm{MgO}$. The thermostatic bath was calibrated at temperatures of 50,65 and $80^{\circ} \mathrm{C}$. The solid reagent was the first to be introduced into the reactor, Shaking speed was calibrated with a digital tachograph and $\mathrm{HCl}$ was then quickly added. The data were read by the electrode and sent to the microcomputer.

In this study, the experiment used a complete factorial design with 3 factors at 2 levels +3 center points, to determine which variables are the most influential on the results. The experiments were conducted at random. The factors chosen were concentration, temperature and time. The analysis of the responses obtained from the planning will show the best concentration, temperature and time for obtaining the highest percentage of $\mathrm{Si}$, the lowest percentage of $\mathrm{MgO}$ and the greatest leached fraction. The table containing the experimental design, levels and answers will be presented in the results and discussions.

After the completion of the leaching procedure, the solution containing solids and liquids was filtered using ultrapure water in and a vacuum pump.

Characterization of the samples was performed through the following tests: X-ray diffraction (XRD) in an $X$-ray diffractometer (Shimatzu, LABX XRD-6000) with copper $\mathrm{K} \alpha(\lambda=1.5405980 \AA \hat{)})$ radiation source, power of $30 \mathrm{kV}$ and $30 \mathrm{~mA}$, for determination of mineralogical phases. To the interpretation and quantification of the results was used the softwere FullProf Suite Toolbar (I450), with the free database COD - Crystallography Open Database - and quantitative method of Rietveld. The BET method enabled the determination of the surface area and pore size distribution of solids. The equipment used in the test was Autosorb I (Quantachrome Instruments) for Windows I.54. ICP-OES (Inductively Coupled Plasma Optical Emission Spectrometry) to identify the elements in the powder sample.

\section{RESULTS AND DISCUSSION.}

In the results calculated (Figure la) by the software FullProf using the refinement of Rietveld from the diffractogram of the XRD of the original sample, it was possible to verify that the powder is composed of, approximately, $76.2 \%$ of $\mathrm{MgO}, 22.8 \%$ of $\mathrm{Si}$ and about I\% of W. From the knowledge of the elementary percentages it was possible to perform the balance of the mass.

$X R D$ analyses were performed in all samples, however, only the diffractogram of the most revealing result will be shown. The Figure $\mathrm{Ib}$ is related to the run (7), according to the experimental design ( $3 \mathrm{M}, 80 \circ \mathrm{C}$ and $120 \mathrm{~min}$ ). It is observed that peaks of $\mathrm{MgO}$ and $\mathrm{W}$ have been reduced drastically. The Si has acute and high peaks, very similar to the standard texture of the element. 

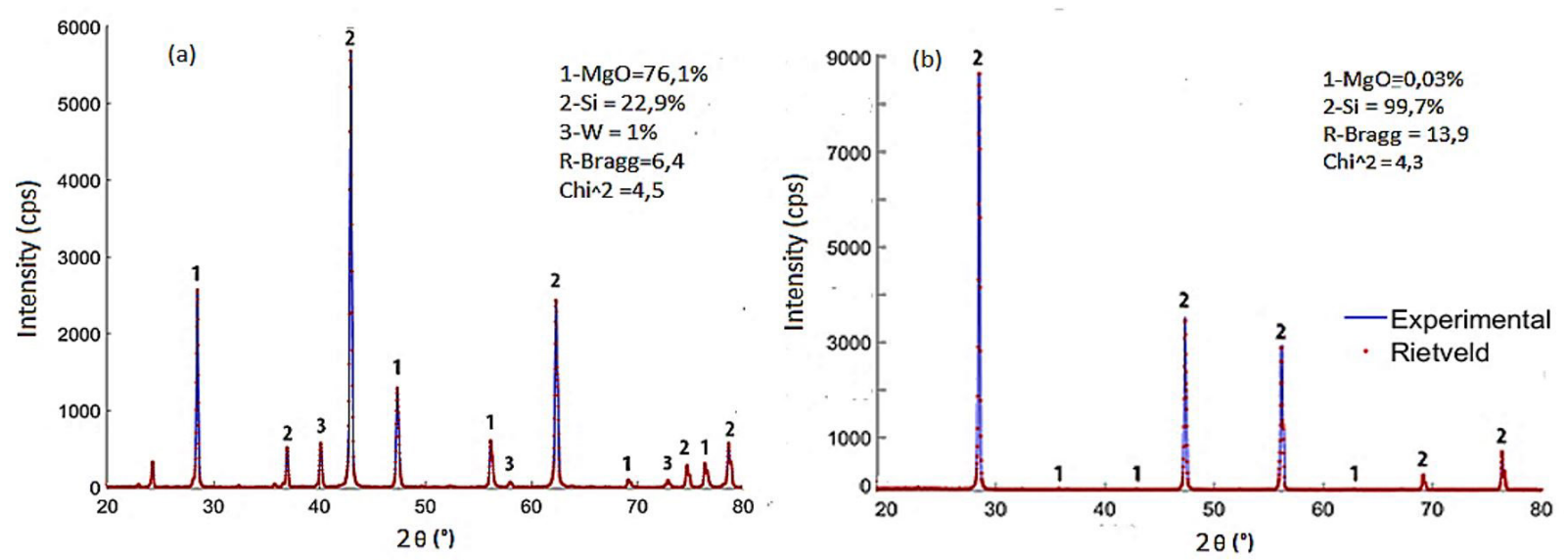

Figure I. X-ray diffractogram of the (a) original powder and (b) run $7\left(3 \mathrm{M}, 80^{\circ} \mathrm{C}\right.$ and $\left.120 \mathrm{~min}\right)$ with Rietveld refinement.

The result percentage of phase calculated by the refinement of Rietveld from diffractogram (Figure lb), presented, approximately, $99.3 \%$ of $\mathrm{Si}$ and $0.7 \%$ of $\mathrm{MgO}$.

Figure 2 shows the isotherm adsorption/desorption of nitrogen in the original sample. The slight concavity observed is relative to the relative pressure $(\mathrm{P} / \mathrm{Po})$ axis, referring to the formation of the monolayer of N2 gas on the surface of the sample. After multilayers are filled on the surface of powder, the inflection in the initiation of the convexity of the curve, in relation to the P/Po axis, occurs. The red line represents a small amount of hysteresis in the desorption of $\mathrm{N}_{2}$. Based on data collected by multipoint BET test and through supplementary estimates of the analysis $\mathrm{BJH}$ (Barret, Joyner and $\mathrm{Halenda}$ ), it can be concluded that the isotherm is type II with hysteresis $\mathrm{H}_{3}$. The surface area of the material has pores of $1.5061 \mathrm{~m}_{2} / \mathrm{g}$. Regarding the diameter of the pores, it is concluded that about $78 \%$ of the pores have a diameter of 22 to $156 \AA$, which is within the limits of the mesopore diameter according to the definition of IUPAC (International Union of Pure and Applied Chemistry). It can be suggested that the powder is at its highest "mesoporous" fraction. The percentage of remaining diameters correspond to approximately $21 \%$ of micropores and $1 \%$ of macro-pores contained in the sample. As for the pore volume, it can be said that $81 \%$ corresponds to mesopores, $\sim 15.5 \%$ to macropores and the remaining $\sim 3.5 \%$ to micropores.

Table I shows the chemical analysis obtained by the ICP-AES technique of leached $\mathrm{Si}$ in run 7 (experimental design) (described in Table 4). The data were compared with the commercial percentage commonly found in metallurgical grade silicon (MGS) [2]. It is concluded that, with the exception of boron, the values are well below the high and low concentration levels of reference. To reduce the concentration of boron, additional treatments should be performed, including: multiple leachates (with formation of complexes), directional solidification, plasma, among others.

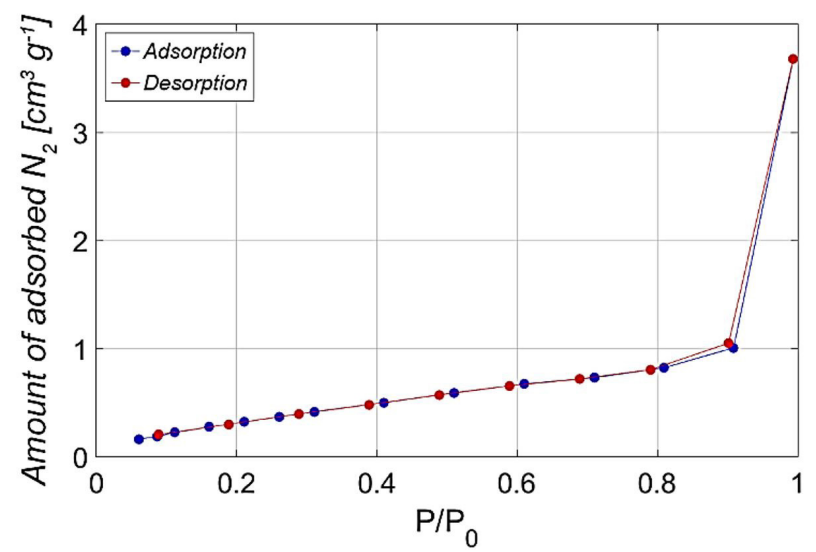

Figure 2. Isotherm adsorption/desorption of the original poder.

According to the results shown in Table I, the powder leachate in run 7 (experimental design) (described inTable 4) can be used in the market of metal alloys and silicones.

The chemical dissolution of $\mathrm{MgO}$ in hydrochloric acid is a liquid-solid reaction in that no solid product is formed. For non-porous $\mathrm{MgO}$, the overall process can be controlled by the chemical reaction on surface $[3,6,9, I 0]$ (Equation I). When the particles of $\mathrm{MgO}$ are dissolved in $\mathrm{HCl}$ in a batch reactor, the consumption of their respective mass fractions can be related (Eq. 2) (where $\mathrm{m}^{0}{ }_{\mathrm{MgO}}$ is the initial amount of $\mathrm{MgO}$ in mass unit, $\mathrm{V}_{\mathrm{R}}$ is the reaction volume and $\mathrm{d} \alpha$ is the fraction of dissolved $\mathrm{MgO}$ ). Equation 2 integrated within the limits of $\left[\mathrm{H}^{+} \mathrm{A}\right.$ to $\left.\mathrm{H}^{+}\right]$and $[\alpha \circ$ to $\alpha]$ results in Equation $3\left(\right.$ Where $\left[\mathrm{H}^{+} \mathrm{i}\right]=10-\mathrm{pHi}, \mathrm{pH}$ at instant i) $[9,10]$. When rearranged, Equation 3 results in leached fraction $\alpha$ (Equation 4), which will be used in the non-isothermal kinetic model. In general, it represents the mass loss rate for a decomposition reaction using Equation 5, often used in thermal analyses (where $d \alpha / d t$ is reaction speed, $f(\alpha)$ the function of the decomposed fraction and $k(T)$ the specific 
Table I. Elements obtained during the leached extract by the ICP-MS technique compared with data on MGS found in the market (concentration mg/l)

\begin{tabular}{|c|c|c|c|c|c|}
\hline \multirow{2}{*}{ Elements } & \multirow{2}{*}{ leach } & \multirow{2}{*}{ SGM-CL* } & \multicolumn{3}{|c|}{ Difference of levels (\%) } \\
\hline & & & high & low & high \\
\hline $\mathrm{Al}$ & 239 & 300 & 5000 & 0,79667 & 0,0478 \\
\hline B & 897 & 5 & 70 & 179,400 & $12,8 \mid 4$ \\
\hline $\mathrm{Ca}$ & 5,6 & 20 & 2000 & 0,28 & 0,0028 \\
\hline $\mathrm{Cr}$ & 2,6 & 5 & 150 & 0,52 & 0,0173 \\
\hline $\mathrm{Cu}$ & 3 & 5 & 100 & 0,6 & 0,03 \\
\hline $\mathrm{Fe}$ & 6 & 300 & 25000 & 0,02 & 0,00024 \\
\hline Mn & 9,6 & 10 & 300 & 0,96 & 0,032 \\
\hline$P$ & 2,6 & 5 & 100 & 0,52 & 0,026 \\
\hline $\mathrm{Ti}$ & 21 & 100 & 1000 & 0,21 & 0,021 \\
\hline V & 2 & I & 300 & 2 & 0,00667 \\
\hline $\mathrm{Zr}$ & 4 & 5 & 300 & 0,8 & 0,01333 \\
\hline
\end{tabular}

*CL- Commercial low.

speed constant). The dependence of $k$ on temperature is given by the Arrhenius (Equation 6) which is generally applied to limited ranges of temperature. By replacing $\mathrm{k}$ from Equation 6 in Equation 7, including the heating rate $\beta=\mathrm{dT} / \mathrm{dt}$ and integrating (where $\mathrm{T}$ is temperature; $A$, the pre-exponential factor; $E$, the activation energy, $R$ the gas constant and $\beta$ the heating ratio) $[4,5,7,8,11,12]$.

The mathematical treatment of the non-isothermal equations can be carried out in accordance with the three methods proposed in the literature: Differential, approximation and integral $[4,5,7,8, I I, I 2]$. For this work, we used the Coats-Redfern integral method (linearized Equation 8) in virtue of its simplicity and wide use in kinetic studies of leaching, dehydration and decomposition of different solid substances. All equations are presented in Table 2.

Figure 3 was obtained through the experimental data adjusted to the deduction of Raschman and Fedoročková $[9,10]$, for the conversion of leaching to $\mathrm{pH}$ variation, the result of which presents the main conversions of the leached fraction over time. Run $7\left(3 \mathrm{M}\right.$ and $\left.80^{\circ} \mathrm{C}\right)$ presented the lowest reaction time for maximum conversion (76\%), i.e., in about 8 minutes it entered into steady state; in this run, silicon was obtained with purity of $99.66 \%$. It was also evident by its curve that the energy intake accelerates the reaction. Run $6\left(3 \mathrm{M}\right.$ and $\left.50^{\circ} \mathrm{C}\right)$ entered into steady state in about 13 minutes. This treatment also resulted in high conversion, with final silicon with purity of $99.7 \%$. Run 10 , on the central point $\left(2 \mathrm{M}\right.$ and $\left.65^{\circ} \mathrm{C}\right)$, resulted in a leached fraction of $48 \%$, even considering leaching stoichiometry, as presented by several studies in the literature. As the material was not pure and no excess amount of reagent $\mathrm{HCl}$ was added, it is assumed that other chemical species contained in the original powder have reacted with $\mathrm{HCl}$; also, the system may have reached a new thermodynamic equilibrium that does not favor total conversion. In runs 3 (IM and $50^{\circ} \mathrm{C}$ ) and 15 (IM and $80^{\circ} \mathrm{C}$ ), only $38 \%$ conversion was achieved; thus, it is clear that this concentration of $\mathrm{HCl}$ is insufficient to react with the amount of $\mathrm{MgO}$ available.

Figure 4 on run $7\left(3 \mathrm{M}\right.$ and $\left.80^{\circ} \mathrm{C}\right)$ shows the plot of the ratio between $\mathrm{I} / \mathrm{T}$ and $\mathrm{In}-[\mathrm{I}-(\mathrm{I}-\alpha) \mathrm{I} / 3] / T 2\}$, non-isothermal

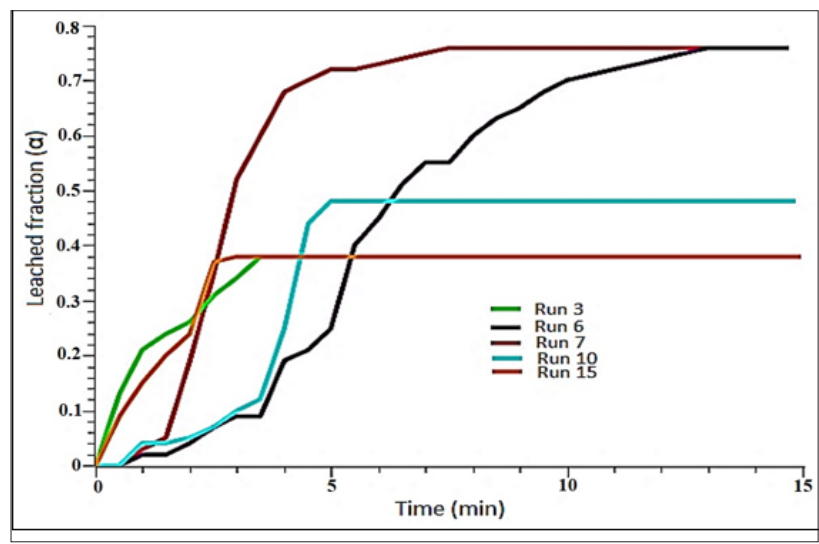

Figure 3. Conversion curves of leached $\alpha \mathrm{MgO}$ at different $\mathrm{HCl}$ concentrations, and reaction temperatures.

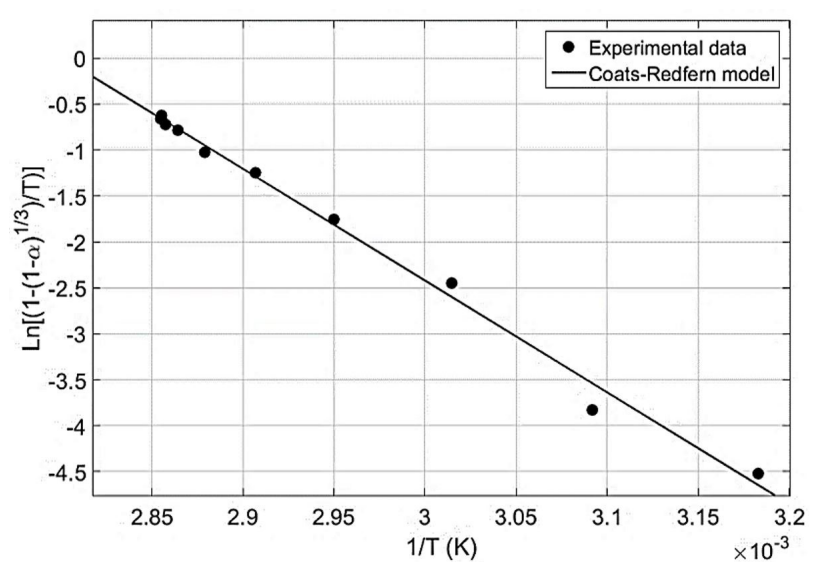

Figure 4. Ratio between $\mathrm{In}-[\mathrm{I}-(\mathrm{I}-\alpha) \mathrm{I} / 3] / \mathrm{T} 2\}$ and $\mathrm{I} / \mathrm{T}$ for determination of the activation energy, form factor and higher apparent rate constant $\mathrm{k}$; graph for run $7\left(3 \mathrm{M} ; 80^{\circ} \mathrm{C}\right)$.

integral Coats and Redfern [12] method (Equation 8), to obtain kinetic parameters, from which it was possible to determine the activation energy $(E)$ with a value of I0I.I8 [kJ/mol]; the linear correlation coefficient (R2) of 
the data adjustment was 99.26, thus showing a great fit, indicating that $\mathrm{HCl}$ is a suitable solvent to promote $\mathrm{MgO}$ dissolution. The pre-exponential factor (A) showed a value of $3.29 E+16$. Based on the values of $E$ and using the Arhenius equation $\left(\ln \mathrm{kc}=-\mathrm{Ea} / \mathrm{R}^{*} \mathrm{I} / \mathrm{T}+\ln \mathrm{A}\right)$, we found the apparent kinetics constant $(k)$ whose value was $21.28 \mathrm{~min}-\mathrm{I}$.

Table 3 contains the conversion data for run 7 , under non-isothermal condition for the first $7.5 \mathrm{~min}$, at intervals of $30 \mathrm{~s}$, for the leached fraction, considering the temperature increase of the reaction medium.

Table 4 shows the complete matrix of experimental design, containing the factors, levels and responses obtained. As the planning was outlined in $2^{3}+3$ center points, the table contains II runs.

The percentages of Si and $\mathrm{MgO}$ ranged from 38 to $99.7 \%$ and from 0.1 to $61 \%$, respectively. As for the leached fraction, the data show that up to $76 \%$ of impurities could be removed from the original powder, in run 7 . The worst standards of silicon purity occurred in run 15, where the levels were IM, $80^{\circ} \mathrm{C}$ and I 20 min. Gel was formed in this run, obstructing the passage of material through the filter.

As experiment has three responses, statistical analysis was performed separately. However, in this study, only data on the leached fraction will be presented.

This statistical analysis evaluated the extraction efficiency of all chemical species after acid treatment, in relation to the original mass contained in powder without treatment; that is, not taking into consideration only $\mathrm{MgO}$, but also the other elements. Table 5 contains the analysis of variance (ANOVA), showing that the model is significant through the F-test (calculated) with a value of 246 , with a small chance of any result different in relation to the $F$ value of $0.01 \%$. The effect of the variable concentration of $\mathrm{HCl}$ or $(\mathrm{H}+)$ " is also significant; the other variables showed no statistical significance and were withdrawn from Table 5, as well as the final equation for the process. As for the lack of adjustment and pure error, the values contained in Table 5 are adequate and the model is well adjusted.

Table 2. Mathematical equations

Font. Adapted [3-12].

Table 3. Data from kinetic equation for non-isothermal leaching

\begin{tabular}{|c|c|c|c|}
\hline $\mathbf{t}(\mathrm{mim})$ & $\alpha_{\mathrm{MgO}}$ & $\mathbf{T}(\mathbf{K})$ & $\operatorname{LN}\left(\left(I-\left(I-\alpha_{M g O}\right)^{\wedge} I / 3\right) / T^{\wedge} 2\right.$ \\
\hline 1,0 & 0,03 & 314,20 & $-16,232$ \\
\hline $\mathrm{I}, 5$ & 0,05 & 323,46 & $-15,600$ \\
\hline 2,0 & 0,19 & 331,72 & $-14,279$ \\
\hline 2,5 & 0,35 & 338,96 & $-13,648$ \\
\hline 3,0 & 0,52 & 344,02 & $-13,2 \mid 4$ \\
\hline 3,5 & 0,60 & 347,32 & $-13,036$ \\
\hline 4,0 & 0,68 & 349,11 & $-12,859$ \\
\hline 4,5 & 0,70 & 349,94 & $-12,816$ \\
\hline 5,0 & 0,72 & 350,20 & $-12,772$ \\
\hline 5,5 & 0,72 & 350,27 & $-12,772$ \\
\hline 6,0 & 0,73 & 350,20 & $-12,750$ \\
\hline 6,5 & 0,74 & 350,14 & $-12,728$ \\
\hline 7,0 & 0,75 & 350,07 & $-12,707$ \\
\hline 7,5 & 0,76 & 350,07 & $-12,686$ \\
\hline
\end{tabular}


The level of significance was determined at $0.1 \%$, and the calculations resulted in an explanation of the variation of the model through $\mathrm{R} 2 \mathrm{adj}=96.64 \%$. The $\mathrm{R} 2$ predicted value corresponds to $94.3 \%$ and the adequacy measure of precision is 5 times as great as the indicated value (Table 6). Final equation of terms (Equation 9).

As shown in Figure 5, as regards the response surface, for the greatest percentage of impurity removal from the original poder to occur, leaching has to be performed with the greatest concentration of $\mathrm{HCl}(3 \mathrm{M})$; the temperature and time do not have significant statistical results. The results of optimization predict, with a desirability factor of $97 \%$, that the best setting is $3 \mathrm{M}, 50^{\circ} \mathrm{C}$ and $60 \mathrm{~min}$ to get silicon with a purity of at least $98 \%$.

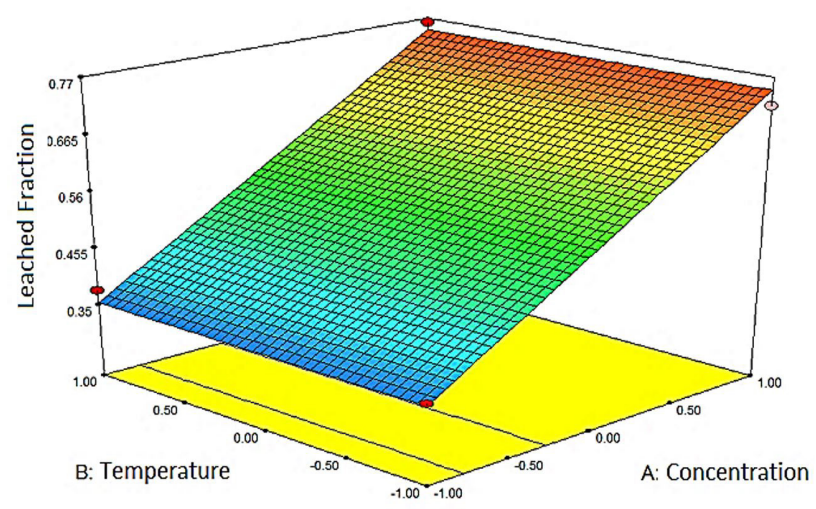

Figure 5. Fraction of response surface leached $x$ temperature $x$ concentration.

Table 4. Planning matrix containing levels, factors and responses

\begin{tabular}{|c|c|c|c|c|c|c|c|}
\hline \multirow[b]{3}{*}{ STD } & \multirow{3}{*}{$\begin{array}{c}\text { Factor Levels I } \\
\text { Factor Levels } 2 \\
\text { Factor Levels } 3 \\
\begin{array}{c}\text { Racing } \\
\text { random }\end{array}\end{array}$} & \multicolumn{3}{|c|}{$\begin{array}{l}(-I)=I M \\
(-I)=55^{\circ} \mathrm{C} \\
(-I)=60 \mathrm{~min}\end{array}$} & \multirow{3}{*}{$\begin{array}{c}\begin{array}{c}(0)=2 \mathrm{M} \\
(0)=65^{\circ} \mathrm{C} \\
(0)=90 \mathrm{~min}\end{array} \\
\text { Resp. I } \\
\begin{array}{c}\% \text { Fraction } \\
\text { of Si }\end{array}\end{array}$} & \multicolumn{2}{|c|}{$\begin{array}{l}(+I)=M \\
(+I)=80^{\circ} \mathrm{C} \\
(+I)=120 \mathrm{~min}\end{array}$} \\
\hline & & Factor I & Factor 2 & Factor 3 & & Resp. 2 & Resp. 3 \\
\hline & & $\begin{array}{c}A: \\
\text { Concentration } \\
M\end{array}$ & $\begin{array}{c}\text { B: } \\
\text { Temperature } \\
\text { Celsius } \\
\end{array}$ & $\begin{array}{c}\text { C: } \\
\text { Time } \\
\text { Min }\end{array}$ & & $\begin{array}{c}\% \text { Fraction of } \\
\text { MgO }\end{array}$ & $\begin{array}{l}\text { Fraction } \\
\text { Leached }\end{array}$ \\
\hline$I$ & 3 & -1 & -1 & -1 & 0,421 & 0,548 & $0,3567 / 5$ \\
\hline 2 & 14 & 1 & -1 & -1 & 0,978 & 0,022 & 0,719634 \\
\hline 3 & 4 & -1 & 1 & -1 & 0,549 & 0,451 & 0,376797 \\
\hline 4 & 8 & I & I & -1 & 0,951 & 0,049 & 0,761091 \\
\hline 5 & 5 & -1 & -1 & I & 0,6 & 0,4 & 0,394358 \\
\hline 6 & 6 & I & -1 & I & 0,997 & 0,003 & 0,739256 \\
\hline 7 & 15 & -1 & I & I & 0,387 & 0,613 & 0,284536 \\
\hline 8 & 7 & I & I & I & 0,993 & 0,007 & 0,76947I \\
\hline 9 & 13 & 0 & 0 & 0 & 0,649 & 0,351 & $0,484 \mid 44$ \\
\hline 10 & 10 & 0 & 0 & 0 & 0,652 & 0,348 & 0,470084 \\
\hline 11 & 11 & 0 & 0 & 0 & 0,757 & 0,243 & 0,524501 \\
\hline
\end{tabular}

Table 5. Analysis of variance (ANOVA) for the response of the leached fraction (red data show significant values)

\begin{tabular}{ccccrr}
\hline SV & QS & DF & MS & $\mathbf{F}_{\text {calculated }}$ & P-value \\
\hline Model & 0,31088 & $\mathrm{I}$ & 0,31088 & 246,59743 & $<0,0001$ \\
Concentraction & 0,31088 & $\mathrm{I}$ & 0,31088 & 246,59743 & $<0,0001$ \\
Curvature & 0,00716 & $\mathrm{I}$ & 0,00716 & 5,68669 & 0,0442 \\
Resedue & 0,01008 & 8 & 0,00126 & & 0,4035 \\
Lack of fit & 0,00848 & 6 & 0,00141 & 1,77327 & \\
Pure error & 0,00159 & 2 & 0,00079 & & \\
Total & 0,32813 & 10 & & & \\
\hline
\end{tabular}

Table 6. Model adjustment determination - leached fraction

\begin{tabular}{|c|c|c|c|}
\hline Standard deviation & 0,035506 & $\mathrm{R} 2$ & 0,968578 \\
\hline Mean & 0,534599 & R2 coordinate & 0,96465 \\
\hline C.V. \% & 6,641667 & R2 predicted & 0,943062 \\
\hline PRESS & 0,018683 & Accuracy adequacy & 21,26253 \\
\hline \multicolumn{4}{|l|}{ Final equation of terminology } \\
\hline \multicolumn{4}{|c|}{ Leached fraction $=+0.55+0.20 * \mathrm{~A}$} \\
\hline \multicolumn{4}{|c|}{ That is: leached fraction $=+0.55023+0.19713 *$ concentration } \\
\hline
\end{tabular}




\section{CONCLUSION}

Acid leaching of the powder product obtained by magnesiothermic reduction for the concentration of silicon metal after the best treatment, it reached $99.66 \%$ purity (ICP-AES). The kinetic study under non-isothermal conditions provided outcomes for obtaining the kinetic parameters which are difficult to obtain in a single run by traditional methods.

The final powder can be considered as metallurgical grade silicon and applied in various industrial areas. All elements contained in the sample had lower rates than the table reference for MGS, commonly found in the market, with the exception of the element boron.

The statistical analysis showed that concentration is the factor that produces a significant effect on the leaching process being studied.

\section{Acknowledgements}

The authors wish to thank CAPES and UFSC for the support to this research.

\section{REFERÊNCIAS}

I Roskill. A report - Silicon and Ferrosilicon: Global Industry Markets \& Outlook. [cited 2015 Mar 4]. Available at: https://roskill.com/market-report/silicon-ferrosilicon/.

2 Luque A, Hegedns S. Handbook of photovoltaic science and engeneering. 2nd ed. Hoboken: John Wiley \& Sons Ltd.; 20II. 157-I79.

3 Banerjee HD, Sen S. Investigations on the production of silicon from rice husks by the magnesium method. Materials Science and Engineering. 1982;52:173-179.

4 Vyazovkin S, Burnham AK. ICTAC Kinetics Committee recommendations for performing kinetic computations on thermal analysis data. Thermochimica Acta. 20I I;520(I-2): I- I9.

5 Demirbas A. Non-isothermal leaching kinetics of braunite in water saturated with sulphur dioxide. Resources, Conservation and Recycling. 1999;26:35-42.

6 Fruhwirth O, Herzog GW, Hollerer I, Rachetti A. Dissolution and hydration kinetcs of MgO. Surface Technology. 1985;24:30I-3I7.

7 Xia H, Peng J, Niu H, Huang M, Zhang Z, Zhang Z, et al. Non-isothermal microwave leaching kinetics and absorption characteristics of primary titanium-rich materials. Transactions of Nonferrous Metals Society of China. 2010;20:721-726.

8 Maitra S, Mukherjee S. Non-isothermal decomposition kinetics of magnesite. Cerâmica. 2007;53:284-287.

9 Raschman P, Fedotoročková A. Study of inhibiting effect of acid concentration on the dissolution rate of magnesium oxide during the leaching of dead-burned magnesite. Hydrometallurgy. 2004;7I:403-4I2.

10 Raschman P, Fedorocková A. Dissolution of periclases in excess of hydrochloric acid: study of inhibiting effect of acid concentration on the dissolution rate. Chemical Engineering Journal. 2006; 1 17:205-21 I.

I I Peng JH, Liu CP. Kinetics of sphalerite leached by $\mathrm{FeCl} 3$ in microwave filed. Zhongguo Youse Jinshu Xuebao. 1992;2:46-49.

12 Coats AW, Redfern JP. Kinetic Parameters from Thermogravimetric Data. Nature. 1964; I:201.

Received: 15 Mai. 2017

Accepted: 26 Abr. 2018 